\title{
LA IDEA DE ACONTECIMIENTO EN LAS FILOSOFÍAS DE ALTHUSSER Y BADIOU COMO FORMA DE REPENSAR LA SUBJETIVIDAD POLÍTICA
}

\author{
The Idea of Event in Althusser and Badiou Philosophy's: a Way to Rethink the \\ Political Subjectivities \\ Ignacio Gordillo
}

Universidad de Buenos Aires

ignacioagordillo@gmail.com

\begin{abstract}
Resumen:
Este artículo aborda los intentos de repensar filosóficamente la política en las obras de Louis Althusser y de Alain Badiou en los momentos en que se ambos se enfrentan teóricamente a la denominada "crisis del marxismo". En el caso de Althusser, viejo representante del estructuralismo marxista, esta reelaboración se nutre de los filósofos pertenecientes a una tradición materialista que también reconoce la contingencia, y se interesa particularmente por Maquiavelo, debido a su particular abordaje de la cuestión política. Por su parte Badiou, antiguo alumno de Althusser, se plantea esta cuestión a través de la categoría del acontecimiento, vinculada a una excepción cuya caracterización ontológica desarrolla en L'Être et l'événement. Finalmente, el trabajo plantea de qué modo para ambos autores la ocurrencia de un acontecimiento contingente puede ligarse al surgimiento de una subjetividad que excede el marco estructural.
\end{abstract}

Palabras clave:

Marxismo, estructuralismo, contingencia, acontecimiento, sujeto.

\begin{abstract}
:
This paper examines the attempts for rethinking philosophically the political in the works of Louis Althusser and of Alain Badiou in the period in which they face theoretically to the so-called "crisis of the Marxism". In Althusser's case, former representative of Marxism structuralism, this project is nourished by the philosophers belonging to a materialistic tradition that also recognizes the contingency, and he is interested particularly for Machiavelli, due to his particular approach to the political question. Badiou, former pupil of Althusser, think this question with the category of the event, linked to an exception characterized ontologically in L'Étre et l'événement. Finally, this article explores in what sense for this authors the occurrence of an event can be linked to the emergence of a subjectivity that exceeds the structural frame.
\end{abstract}




\section{Keywords:}

Marxism, Structuralism, Contingency, Event, Subject.

Recibido: $31 / 07 / 2018$

Aceptado: 13/06/2019

\section{LOS LÍMITES DEL MARXISMO PARA PENSAR LA POLÍTICA}

La "crisis del marxismo" fue un fenómeno político marcado principalmente por las divisiones del movimiento comunista internacional, pero que también tuvo una importante faceta académica que se manifestó a fines de la década del setenta en algunos debates realizados en Europa -principalmente en Italia, Francia y España- en los que se plantearon las limitaciones de la teoría marxista y de las organizaciones comunistas para hacer frente a nuevos desafíos políticos. En el caso de dos intelectuales franceses como Louis Althusser y Alain Badiou, atravesar esta crisis implica una apertura en sus filosofías hacia la idea de acontecimiento como punto de partida para formular un pensamiento novedoso de la política emancipadora y de la constitución de nuevas subjetividades políticas, a distancia del carácter necesario y totalizante de la interpretación de la dialéctica en las versiones del marxismo más ortodoxo.

Hacia fines de los setenta, Althusser parece perder la confianza en su proyecto de rehabilitación de la "auténtica" teoría marxista (a la cual le endilgaba un rol decisivo en la resolución de los avatares de la política), a la vez que comienza a criticar abiertamente algunos de los lineamientos del régimen soviético y del Partido Comunista Francés (PCF). En efecto, en 1977 presenta en un debate en Venecia una conferencia que se titula "¡Por fin la crisis del marxismo!". Al año siguiente, continúa con esta temática en algunos artículos como "El marxismo como teoría finita" y "El marxismo hoy", además de escribir el texto Marx dentro de sus límites (inédito hasta 1995). En todos estos trabajos reflexiona acerca de las causas de la crisis del marxismo, crisis a nivel histórico y político, pero cuyo alcance él decide examinar fundamentalmente en su aspecto teórico (sin apoyar por ello la tesis de la "omnipotencia de las ideas", según la cual las falencias teóricas serían las culpables de los fracasos históricos del marxismo).

En la conferencia de 1977, Althusser sostiene que no se trata sólo de atribuir las dificultades a la nociva herencia estalinista. Luego de haber sostenido en la década de los sesenta un proyecto de "vuelta a las fuentes" para recuperar la cientificidad y la filosofía latente en la obra marxiana de madurez, el filósofo francés reconoce que la tradición teórica marxista "no es pura, sino conflictiva, que contrariamente a las palabras apresuradas de Lenin, el marxismo no es un 'bloque de acero', sino que comporta dificultades, contradicciones y lagunas que han jugado (...) su papel en esta larga crisis" (Althusser, 2015: 293).

En esa línea, como punto de partida del libro Marx dentro de sus límites, Althusser señala que el propio Marx designó su obra como "crítica" y se preocupó por evitar que ella sea interpretada como una nueva filosofía de la historia o como un sistema 
teórico producido de forma acabada (Althusser, 2003: 29-30). También destaca que Marx se distingue de toda filosofía política idealista y se asemeja al materialismo de Maquiavelo al descreer del poder autónomo de las ideas. En el Manifiesto Comunista se afirma que las ideas de los comunistas no dependen de sí mismas, sino que expresan la lucha política del proletariado; es este movimiento rea/lo que abre la vía al comunismo'. La eficacia de las ideas depende en todo caso de la situación de las relaciones de fuerza entre las clases (Althusser, 2003: 65).

Según la interpretación althusseriana, Marx supo ser consecuente con esta tesis materialista y aplicarla a su propia obra adoptando una tópica para situar y presentar sus ideas teóricas bajo dos formas diferentes. En primer lugar, el autor de El Capital presenta a su teoría como un intento de explicar una realidad global que es el capitalismo y, en consecuencia, ella se aplicaría a todo ese espacio. Pero, en segundo lugar, Marx también se permite situar a sus teorías en un lugar más preciso dentro de esa realidad de conjunto y considerarlas entre las formas ideológicas que tienen resonancias en la lucha de clases, esto es, la política. De este modo: "las ideas teóricas cambian de forma: pasan de la forma-teórica a la forma-ideología" (2003: 66).

Por otro lado, en este asunto del reexamen del marxismo, Althusser señala cada vez con mayor insistencia la importancia de la intervención, no solamente de los intelectuales o el partido, sino también de las masas obreras y populares. En ese sentido, según él, el estallido de la crisis también está condicionado de manera positiva por la aparición y la acción de nuevos movimientos populares (en aquellos años, se refiere principalmente a los movimientos políticos surgidos en Portugal, Grecia y España tras el fin de sus dictaduras). El renacimiento del marxismo requiere entonces prestar atención a estas iniciativas y no reducir la política a sus formas burguesas tradicionales de organización y representación (en el Estado, el partido o el sindicato): hay que "saber escuchar la política allí donde ella nace y se hace" (Althusser, 2015: 308).

En resumen, Althusser en este momento de crisis ya no considera que sea menester realizar un esfuerzo de investigación en el corpus teórico marxista para restituir al "verdadero" Marx científico, distinguible de las "desviaciones" ocasionadas por las interpretaciones dogmáticas o humanistas. El nuevo desafío es realizar una lectura crítica que permita enunciar los límites y deformaciones del marxismo, principalmente a la hora de pensar la política, y la forma de superarlos desde una óptica materialista.

\section{EL MATERIALISMO ALEATORIO}

En su exploración de las vías para contrarrestar las limitaciones de la teoría marxista y reubicar sus aportes esenciales, Althusser se dedica posteriormente a profundizar su investigación de una singular corriente intelectual. Desde mediados de los setenta, sin abandonar su posición materialista, su perspectiva filosófica rechaza la pretensión totalizante y determinista de la dialéctica al plantearse la dimensión de la

${ }^{1}$ Cfr. Marx y Engels (2008), Manifiesto Comunista, Buenos Aires, Prometeo, p. 59. 
contingencia ${ }^{2}$. Finalmente, en los ochenta, cuando se aleja definitivamente del PCF por considerarlo una estructura esclerótica opuesta a cualquier esfuerzo de pensamiento, la idea althusseriana de elaborar una filosofía para el marxismo se plasma en lo que llama el "materialismo del encuentro", una corriente filosófica que describe en "La corriente subterránea del materialismo del encuentro" (texto de 1982 publicado en 1994) ${ }^{3}$.

La también llamada "filosofía del encuentro" es designada desde el principio por Althusser como materialista para demarcar su tendencia y su oposición radical a todo idealismo. Aquello que -desde su conferencia Lenin y la Filosofía- él denomina el "campo de batalla" filosófico se presenta ocupado entonces por el enfrentamiento del materialismo aleatorio versus todas las variantes del idealismo:

un materialismo del encuentro, así pues de lo aleatorio y de la contingencia, que se opone (...) a los distintos materialismos que suelen enumerarse, incluso al materialismo comúnmente asociado a Marx, Engels y Lenin que, como todo materialismo de la tradición racionalista, es un materialismo de la necesidad y la teleología, es decir, una forma transformada y encubierta de idealismo (Althusser, 2002: 32).

Así como niega toda teleología, el materialismo del encuentro tampoco da lugar a un Sujeto (ya fuese Dios o el proletariado), sino a lo que Althusser denomina un "proceso sin sujeto" que impone a los individuos a los que envuelve el orden de su desarrollo sin un fin predeterminado. Esta fórmula de "proceso sin sujeto", remite a sus reservas previas respecto de dicha categoría filosófica. Postulada por primera vez hacia 1969, ella retoma la idea de proceso de Hegel, pero desiste de incorporar a la categoría de Sujeto ya que juzga que ésta funciona como un garante esencial de las ideologías presentes en las diferentes concepciones de la teoría del conocimiento, la moral, el Derecho, la política, la Historia, etc. En esa línea, en su famoso texto Ideología y Aparatos Ideológicos del Estado, Althusser (1974) sostiene la tesis de que la noción de sujeto, contrariamente a su representación idealista, es un producto de la interpelación por la cual la ideología dominante moldea y asigna a los individuos

\footnotetext{
${ }^{2}$ En su lectura de los manuscritos y textos de de Althusser publicados póstumamente, Goshgarian, un especialista en el pensamiento althusseriano, enfatiza en contraposición a otros comentadores que las referencias a Epicuro como parte de una tradición materialista de la filosofía que subraya la contingencia ya pueden encontrarse en escritos fechados desde mediados de los setenta. Goshgarian, G. M. (2017), "Prefacio" en Althusser, L., Ser marxista en filosofía, Madrid: Akal, pp. 7-26.

${ }^{3}$ Los textos que plasman el pensamiento de Althusser en la década de los ochenta han permanecido desconocidos durante varios años. Luego del homicidio de su mujer en 1980 y su posterior internación psiquiátrica (que se prolongó hasta 1983), Althusser se condenó al silencio y su legado filosófico fue abruptamente reprimido. Por este motivo, casi la totalidad de los textos de esta época no van a ser publicados sino hasta después de su muerte por el Institut Mémoires de l'édition contemporaine (IMEC).
} 
concretos un lugar en la estructura social. Dado que siempre hay ideología, los individuos son siempre-ya sujetos, es decir, seres sujetados a su estructuración ${ }^{4}$.

En esta recuperación de una corriente materialista, Althusser ubica como referente primordial al pensamiento de Epicuro ${ }^{5}$. Antes de la formación del mundo, la física del epicureísmo (complementada luego por Lucrecio) relata una lluvia de átomos cayendo continuamente en paralelo en el vacío hasta que, de manera azarosa, sobreviene el Ilamado clinamen, es decir, una desviación infinitesimal que provoca el primer encuentro entre átomos ${ }^{6}$. Luego, si el encuentro es duradero (lo cual también es aleatorio y puede no suceder), da lugar a la conformación de un mundo.

Una vez consumado este hecho de que "hay mundo", se instaura el reino de la Razón, la Necesidad, el Sentido y el Fin, etc.; pero la tesis fundamental que Althusser rescata de Epicuro es que dicho suceso es efecto de la pura contingencia del encuentro (y vale notar que el término encuentro en su voz francesa rencontré posee este matiz de coincidencia o casualidad). En consecuencia, desde el enfoque del materialismo aleatorio, la filosofía "ya no es el enunciado de la Razón y del Origen de las cosas, sino teoría de su contingencia y reconocimiento del hecho, del hecho de la contingencia, del hecho de la sumisión de la necesidad a la contingencia..." (Althusser, 2002: 34).

En segundo término, aproximarse a la concepción althusseriana del encuentro o el acontecimiento en el ámbito de la política requiere de modo ineludible conocer el examen que realiza de Maquiavelo como miembro de esta tradición filosófica ${ }^{7}$. A partir de su lectura conjunta de El Príncipe y los Discursos sobre la primera década de Tito Livio, Althusser considera que los principales aportes del autor florentino no

\footnotetext{
${ }^{4}$ En esa línea, en un artículo de 1973, Althusser se muestra contrario a la tesis del humanismo marxista de que "el hombre hace la historia", y propone desembarazarse de esta clase de ideologías que fetichizan al hombre y presuponen su libertad para trascender la historia. Cfr. Althusser, Para una crítica de la práctica teórica. Respuesta a John Lewis, Buenos Aires: Siglo XXI, 1974.

${ }^{5}$ Althusser ubica en esta tradición a autores como Epicuro, Lucrecio, Maquiavelo, Spinoza, Hobbes, Rousseau en el Segundo Discurso, Marx e incluso tangencialmente a Heidegger.

${ }^{6}$ Cfr. Epicuro, Epístola a Heródoto, 43. También: Lucrecio, De la Naturaleza, Libro II, 251 293.

7 Althusser dedicó cursos a Maquiavelo en 1962 y 1972, a partir de los cuales ordenó un texto hasta 1975 para su publicación. Asimismo, en 1978 presentó una conferencia en 1978 titulada "La soledad de Maquiavelo", basada en las conclusiones del curso de 1972. Sin embargo, en los años posteriores y en la década de los ochenta, nuevamente introdujo modificaciones al texto que fue publicado en 1994 con el título Maquiavelo y nosotros. Según subraya Toni Negri, en su prefacio a esta edición póstuma, los agregados remarcan el componente aleatorio y fortuito de todo acontecimiento que abre la posibilidad, de ese modo, a la intervención constitutiva de la subjetividad. Esto señalaría una nueva posición de Althusser, distante del determinismo dialéctico, que Negri denomina Kehre o "giro" del pensamiento filosófico althusseriano. Cfr. Negri, Antonio (2004), "Introducción. Maquiavelo y Althusser" en Althusser, Louis. Maquiavelo y nosotros, Madrid: Akal, pp. 11-40 (principalmente, pp. 18-19 y p. 31).
} 
pertenecen al campo de la ciencia política -como se cree habitualmente-, sino que son filosóficos.

Maquiavelo es un representante del materialismo del encuentro pensado a través de la política y, como tal, enfatiza el carácter contingente de toda construcción política singular. La originalidad de su obra reside en que "no piensa el hecho consumado de las monarquías absolutas, ni su mecanismo [tal como lo hacen los teóricos del derecho natural], sino el hecho que hay que consumar" (Althusser, 2015: 339). En efecto, en lugar de teorizar sobre el Estado ya constituido, se preocupa por pensar lo nuevo, la fundación de un Estado en ausencia de condiciones favorables. Asimismo, Althusser destaca la "soledad" de Maquiavelo, quien se distanció del tono moralizante de la filosofía política clásica y de la religión, a la vez que desmitificó el relato de los orígenes del Estado moderno creado por la filosofía moderna (2015: 341-342) .

Los escritos de Maquiavelo abordan las condiciones de posibilidad de existencia histórica de un Estado a partir de un problema específico: la constitución de la unidad italiana mediante un Estado nacional. En ese sentido, da cuenta del vacío político italiano a partir del cual el nuevo Estado debería comenzar y tomar consistencia. Sin embargo, Althusser no deja de subrayar que "este vacío político es en primer lugar un vacío filosófico" ya que no presupone "ninguna Causa que preceda a sus efectos, ningún Principio de moral o de teología (Althusser, 2002: 39).

La Italia del siglo XVI es descripta en El Príncipe como un país fragmentado y atomizado, situación comparable a la lluvia epicúrea de elementos aislados. El texto maquiaveliano debe plantearse entonces cuáles son las condiciones para que ocurra la desviación y el consiguiente encuentro duradero que posibilite cumplir con la tarea histórica de fundar el Estado nacional italiano. Luego de ofrecer en sus Discursos una teoría de las leyes de la historia y una tipología de gobiernos, el pensador florentino llega a la conclusión de que ninguno de esos gobiernos sirve para lograr su objetivo de fundar un Estado que perdure. Maquiavelo rechaza todos los Estados y príncipes preexistentes y prefiere postular que la nueva unidad debe lograrse a través de un Príncipe nuevo en un Principado nuevo. La teoría del acontecimiento permanece indeterminada, ya que se trata de un Príncipe aún sin nombre y de una región también indefinida que deben encontrarse para, a partir de ese punto atomístico, aglutinar las fuerzas que permitan fundar el nuevo Estado nacional. Esta indefinición del lugar y del sujeto expresan para Althusser una toma de posición política de Maquiavelo: su pretensión de comenzar la tarea del porvenir a partir de nada y de nadie (2004: 106).

El acontecimiento del advenimiento del nuevo Príncipe depende del encuentro aleatorio entre lo que Maquiavelo Ilama la fortuna y la virtù. En efecto, por un lado, se hallan las condiciones de una coyuntura, que es ella misma una con-junción

\footnotetext{
${ }^{8}$ Según Althusser, una tesis de Maquiavelo en los Discursos es que en el origen de todo gobierno se halla el azar o la Fortuna pues al principio todos los hombres estaban dispersos. Al igual que en Epicuro, el azar se asocia con la dispersión (Althusser, 2004: 72).
} 
fortuita que ha tenido lugar ${ }^{9}$; por otro lado, una capacidad subjetiva que no hace referencia a ningún atributo moral sino a la cualidad del Príncipe de aprovechar la coyuntura favorable o la oportunidad que se le presenta (Althusser, 2004: 104). Finalmente, para que el encuentro sea duradero y se cumpla la tarea fundacional, se requiere la virtù política del Príncipe Nuevo en el sentido de que debe saber gobernar estratégicamente, es decir, transformar las condiciones materiales favorables de una situación en una estructura política estable.

En resumen, para el materialismo aleatorio nada garantiza que de la realidad del hecho consumado, aún si éste permaneciese un largo tiempo, se pueda desprender su necesidad: "La historia no es más que la revocación permanente del hecho consumado por parte de otro hecho indescifrable a consumar, sin que se sepa, ni de antemano ni nunca, dónde ni cómo se producirá el acontecimiento de su revocación" (Althusser, 2002: 39). Aún sin negar la influencia de la historia consumada, el materialismo aleatorio permite pensar en otro tipo de historia, la historia en presente, abierta a un futuro incierto y, por lo tanto, aleatorio; de allí su riqueza para pensar la política.

El materialismo del encuentro parte del reconocimiento de que cada encuentro es aleatorio en sus orígenes porque nada lo garantiza, el encuentro puede tener o no lugar; e incluso una vez que ya ha tenido lugar, su ser está marcado por la aleatoriedad. Por otro lado, también todo encuentro es aleatorio en sus efectos, dado que la determinación del ser resultante del encuentro no puede preverse a partir de los elementos que concurren en él. Esta reunión azarosa sólo puede considerarse como "determinada" desde una mirada retrospectiva, mirando hacia atrás una vez ya conocido su resultado: "en lugar de pensar la contingencia como modalidad o excepción de la necesidad [tal como se lo pensaba anteriormente], hay que pensar la necesidad como devenir-necesario del encuentro de contingentes" (Althusser, 2002: 60). Asimismo, cada figura de la historia y Estado del mundo no son resultados necesarios, sino provisionales y en un doble sentido: en el sentido de que pueden ser suplantados, y también porque hubiesen podido no advenir jamás, salvo por un encuentro.

En definitiva, en esta postura de asumir el carácter contingente de toda estructura, los filósofos materialistas Epicuro y Maquiavelo (éste último en la dimensión política) son resaltados por Althusser como representantes de una corriente que implica una crítica radical a aquella filosofía tradicional que pretende decir la verdad última sobre el conjunto de los discursos y prácticas sociales. Este tipo de filosofía de lo aleatorio sirve entonces para pensar la apertura del mundo hacia el acontecimiento y la singularidad de todas las prácticas vivas, incluyendo la política.

\section{BADIOU Y EL RECOMIENZO DEL MARXISMO}

Alain Badiou fue alumno de Althusser en la École Normale Supérieure (ENS) de París a principios de los sesenta y realizó sus primeras publicaciones filosóficas bajo la égida del estructuralismo marxista impulsado por su maestro. Después de los eventos

${ }^{9}$ En lengua francesa se puede apreciar la raíz etimológica que vincula los términos conjoncture y conjonction, matiz que se pierde en lengua española. 
de Mayo de 1968, éste vínculo va a modificarse bruscamente dado que Badiou, sacudido subjetivamente por la novedad de los sucesos, ataca enérgicamente al PCF donde se encuadraba Althusser, quien en esos años todavía confiaba en la posibilidad de reformar este partido (Badiou, 2016: 31). Más adelante, a fines de los setenta, se puede decir que Badiou se mantiene de todos modos interesado en el proyecto althusseriano de reformular la dialéctica materialista, aunque desde una postura particular. En efecto, el libro Théorie du sujet, basado en clases de su seminario entre 1975 y 1979, aborda la cuestión de la dialéctica inspirándose en autores tan diversos como Hegel, Mallarmé, Lacan, Mao y Lenin. En esa línea, esta obra incluye una clase de fines de 1975 dedicada al atomismo griego dentro del cual se ubica a Epicuro, filósofo que, como ya se mostró, fue también utilizado por Althusser con el objetivo de pensar la primacía de lo aleatorio.

En su libro, Badiou considera que la dialéctica no es neutral por lo que ella es dividida en dos vertientes: una estructural y otra histórica. El atomismo es situado en esa primera concepción de la dialéctica que, al abordar el tema de las contradicciones, tiene como principal desafío explicar cómo se realiza el pasaje de una diferencia fuerte a una débil. En efecto, el punto de partida del atomismo griego es la estéril rigidez que muestra la fuerte distinción entre el vacío, por un lado, y la multiplicidad de átomos, por otro. Para pasar de esta diferencia fuerte a una débil, la filosofía atomista desdibuja aquella oposición primordial a partir de la operación del término transicional que es el clinamen, esto es, la desviación azarosa que permite la combinatoria de átomos y da lugar al mundo. Sin embargo, finalmente para la dialéctica estructural es fundamental que el clinamen sea abolido: a pesar que él sea el principio de la existencia, debe ausentarse posteriormente de todos sus efectos. Es un acontecimiento del cual no quedan huellas en el mundo. Badiou designa a esto la operación del término evanescente que "hace pasar de la diferencia fuerte a la débil, al marcar la cualidad heterogénea, y al abolirse enseguida" (Badiou, 2008: 84).

Por esta razón, Badiou, interesado por la cuestión del sujeto post-mayo del 68, es crítico respecto de la vertiente estructural de la dialéctica reflejada en el atomismo griego debido a que, si bien piensa en términos de procesos y de contradicciones, al final de cuentas hace prevalecer el componente estructural sobre el histórico al reducir toda diferencia a una mera distinción posicional e intercambiable. Es decir, cuando esta clase de dialéctica se encuentra con lo real o la efectividad histórica no hace más que subordinar esa novedad a una estructura sin sujeto (Badiou, 2008: 76).

Por otra parte, en un contexto intelectual dominado por la creciente difusión del pensamiento de los llamados "nuevos filósofos", ex militantes de izquierda que pasaron a criticar fervorosamente los postulados del marxismo y a los gobiernos socialistas; en una clase de noviembre de 1977 también publicada en Théorie du sujet, Badiou sostiene que existen dos actitudes ante esta avanzada antirrevolucionaria. Contrariamente a la ortodoxia marxista que intenta defender ciegamente sus ideas, Badiou plantea la necesidad de reconocer que el marxismo está en crisis, ya que de dicha ceguera se alimenta justamente el éxito de los pensadores "renegados". La alternativa correcta consistiría entonces en emprender una refundación del marxismo: "Defender el marxismo, hoy es defender una debilidad. Hay que hacer el marxismo" (2008: 206). 
Este tema de la crisis y de la refundación va a ocupar posteriormente gran parte de su libro On peut penser la politique?, publicado en 1985 y basado en dos intervenciones realizadas por Badiou en 1983 y 1984 en la ENS, en el marco del seminario sobre "la retirada de lo político" por invitación de Jean-Luc Nancy y Philippe Lacoue-Labarte. En efecto, la primera parte del texto examina la "crisis del marxismo" desde una perspectiva que no la reconoce tanto como una cuestión teórica o de pérdida de capacidad de análisis, tal como se subrayaba en Althusser, sino como una crisis política originada en el agotamiento de las referencias históricas y sociales en las que se apoyaba: la referencia estatal de los Estados socialistas; la referencia popular de las guerras de liberación nacional y la referencia social ubicada en el movimiento obrero organizado. La crisis del marxismo es el "derrumbe por etapas de ese dispositivo de referencias (...). Su crédito se ha agotado" (Badiou, 1990: 20).

Ante esta escena desoladora, la propuesta badiouana es pensar la destrucción del marxismo como sujetos como paso previo a su recomienzo. De este modo, los militantes adquieren un rol protagónico en esta tarea de recomposición: un marxista de nuevo tipo es "el que está en la destrucción del marxismo en posición subjetiva, que pronuncia de manera inmanente lo que debe morir, y que por lo tanto muere él mismo, disponiendo esa muerte como causa de una recomposición de la política" (Badiou, 1990: 37). La topología de la subjetividad marxista consiste entonces en una torsión desde el lugar destruido para no acomodarse dentro de la ortodoxia marxistaleninista, ni en la exterioridad liberal-conservadora del antimarxismo.

Efectuar dicha torsión implica también desprenderse del triunfalismo de la etapa anterior que culmina con el fin de la Revolución Cultura Proletaria en China. Badiou constata que los grandes sucesos de la política de aquellos años, como la "Revolución Iraní" y el movimiento SolidarnosC, no se sitúan al interior del marxismo (1990: 37).

Asimismo, ante el problema de reiniciar el marxismo como pensamiento político emancipador, Badiou acude al gesto original de Marx. El marxismo comenzó a mediados del siglo XIX marcando un corte y una interpretación: esto fue lo que hizo Marx en el Manifiesto cuando señaló que "hay movimiento revolucionario obrero". Luego, en el curso de la historia se dieron los avances en el movimiento obrero, la conformación de Partidos y su arribo al Estado. Todo esto le fue permitiendo al marxismo construir una representación de sí mismo, su puesta en ficción, hasta convertirse en un pensamiento autorreferencial de esta "marxización". La tesis badiouana es que con el advenimiento de la crisis, el ciclo de autorreferencialidad del marxismo está cerrado y el comienzo precedente ha dejado de valer. Las verdaderas políticas ya no son contemporáneas de ese ciclo, "sino de un 'hay' histórico-político del que hay que volver a pensar la dimensión emancipadora" (Badiou, 1990: 40).

Imitando el gesto de Marx, entonces, el recomienzo debe pensarse nuevamente a partir del "hay" relativo a un corte. Se trata de estar atentos a lo que "hay" para poder proponer hipótesis políticas inaugurales, más precisamente, de (re)formular "la hipótesis de una capacidad política adecuada a la no-dominación" (Badiou, 1990: 40). En cuanto a las fuentes de este recomienzo del pensamiento emancipador 
entonces, además de una necesaria crítica del ciclo de marxización y la deconstrucción del marxismo-leninismo como época metafísica del pensamiento político, ocupan un lugar privilegiado los ya mencionados acontecimientos políticos de la época, en tanto constituirían una chance de renovación de la hipótesis emancipadora del comunismo (Badiou, 1990: 42).

En esa línea, la segunda parte de On peut penser la politique? marca el rumbo del autor hacia un pensamiento de la política desde nuevas coordenadas y conceptos que permiten pensar la interrupción de la dominación sin presuponer un sujeto o un antagonismo previos. En efecto, Badiou presenta una primera formulación de una teoría del acontecimiento y de la intervención subjetiva en el campo de la política dado que, al igual que Althusser, se preocupa por registrar aquellos movimientos de la época cuya singularidad parece rebasar los esquemas marxistas de pensamiento.

Badiou afirma que la esencia de la política se sitúa en el "hay" del acontecimiento, el cual debe distinguirse de la normalidad de los hechos en los que se suele concentrar la crónica de la política (paradigmáticamente, en el hecho electoral) (Badiou, 1990, p 46). Un acontecimiento es definido como un disfuncionamiento de la estructura de la situación que no se infiere automáticamente de ella, sino que es producto de una interpretación particular. Se liga entonces a una intervención subjetiva que lo aborda como una especie de síntoma: "Llamo intervención a los enunciados y hechos supernumerarios a través de los cuales se efectúa la interpretación que desprende el acontecimiento" (Badiou, 1990: 52). La decisión de ser fiel al acontecimiento sólo está anudada a la hipótesis que afirma la existencia de una política de la no-dominación; hipótesis introducida por Marx que funciona como un axioma a partir del cual deben desplegarse sus consecuencias.

En su texto, Badiou parece separarse de una perspectiva dialéctica tradicional al sostener que la política rompe con la situación o que hace a un lado los hechos. Sin embargo, él reconoce la importancia de resolver la cuestión de la dialéctica para poder pensar la política y se propone recrearla a través de nuevas referencias (tal como lo intentó en Teoría del Sujeto) que permitan despejarla de cualquier tipo de determinismo $^{10}$. La dialéctica es definida ahora como una doctrina del acontecimiento, desregulada, en conflicto con la representación y toda imagen representativa de la política. Ella se asienta en un método interpretativo, pero en un sentido particular, ligado al de la clínica psicoanalítica: se trata de una interpretación-corte o interrupción interpretativa que acorrala un punto irrepresentable donde se toca un "real", y que luego es legible por sus efectos. El pensamiento dialéctico abre una brecha en el dispositivo de las representaciones cuando se topa con el síntoma (el acontecimiento) que es interpretado como una hipótesis de capacidad en la que retroactivamente se revela un efecto de sujeto (Badiou, 1990: 60-61). En definitiva, si bien no abandona totalmente el término dialéctica en esta obra, Badiou hace referencia a aquello que comienza en un acontecimiento excepcional e implica una apuesta hipotética que desestructura el

\footnotetext{
10 Asimismo, para Badiou tampoco es suficiente para superar esa imagen mecanicista el fortalecimiento de la referencia materialista, tal como intenta Althusser con Epicuro y Lucrecio (Badiou, 1990: 58).
} 
orden de lo posible; conceptos que fundamentará ontológicamente en L'Être et l'événement.

Badiou reconoce asimismo que la intervención subjetiva ligada a un acontecimiento está sometida a la coyuntura y que en el ámbito de la política se está sometido a la situación incluso con especial urgencia, razón por la cual ella es particularmente difícil. La intervención política se califica únicamente por su efecto (victorioso o nulo), retroactivamente, por eso la incertidumbre y la anticipación son constitutivas de este acto. Dicho esto, Badiou afirma que en la política es preferible apostar e intervenir cuando se llega a los límites justificados por el análisis. Si bien es cierto que esta intervención puede tener un efecto nulo, para Badiou una "derrota intrapolítica" reside más en la incapacidad para distinguir a la política respecto de un análisis ordinario de la situación. En efecto, el análisis de las condiciones históricas es imprescindible pero debe ser tomado desde una perspectiva militante. Llegar a los límites de ese análisis y detenerse en esa certidumbre improductiva equivale a fracasar políticamente (Badiou, 1990: 71). En fin, la verdadera política empieza cuando se realiza una intervención subjetiva en apuesta que va más allá de un análisis supuestamente objetivo de la situación, ella asume riesgos en nombre del acontecimiento.

\section{EL ACONTECIMIENTO Y LA INTERVENCIÓN DEL SUJETO}

A mediados de los ochenta, Badiou comienza la redacción de su obra magna, L'Être et l'événement (1988), en la cual asienta nuevas bases para demostrar que la filosofía es aún posible $y$, a la vez, para poder pensar aquello que sucede "afuera" de ella (por ejemplo, en la política) a través de la idea de acontecimiento. Este lugar clave que Badiou otorga a dicha categoría dentro de su teoría no viene acompañado de una impugnación del interés de la tradición filosófica por la cuestión ontológica, ya que es el acontecimiento es concebido como un suplemento respecto de la estructura del ser.

La tesis inicial del libro es que la exposición del ser-en-tanto-que-ser corresponde exclusivamente al discurso de la matemática. Al mismo tiempo, dado que para Badiou el ser en sí mismo se sustrae y no se presenta directamente ni indirectamente a través de ningún tipo de experiencia, la ontología matemática sólo puede exponer el ser en su presentación efectiva. El punto de partida de esta ontología es que lo múltiple "sin Uno" es la ley del ser, es decir, el ser-en-tanto-que-ser es multiplicidad pura (1999: 33). De ese modo, la idea de "lo Uno", de suma importancia desde los inicios de la historia de la filosofía occidental, pierde su lugar primordial para pasar a designar sólo la operación de cuenta sobre lo múltiple y el resultado de unidad que surge de la determinación de sus elementos. En síntesis, el ser en sí mismo se concibe como una multiplicidad infinita e inconsistente, mientras que lo presentado es resultado de la acción estructurante de lo uno. Badiou denomina situación a esta presentación estructurada de la multiplicidad a través de su operación de "cuentapor-uno". La situación es un régimen normal donde todo lo que acaece es contabilizado y aprehendido por un saber.

Por otro lado, vale notar que lo múltiple puro e inconsistente sólo puede ser presupuesto a partir del axioma que dicta que lo uno no es, anterior a la cuenta-por- 
uno que implica toda situación. Esto permite decir que, al escapar a dicha cuenta, es impresentable $y$, por nunca presentarse, es una nada. Sin embargo, este ser-nada no equivale a no-ser, sino que existe como nada. Badiou denomina vacío a esta nada impresentada en la situación. El vacío es entonces el nombre propio del ser anterior a su simbolización y está incluido universalmente en todo conjunto (Badiou, 1999: $70)^{11}$.

A su vez, existe una segunda cuenta, una cuenta sobre la cuenta, por la cual todos los elementos presentados en la situación son re-presentados y agrupados. Esta meta-estructura que, por conveniencia metafórica con la política, Badiou denomina "estado de la situación" (1999: 113), tiene como propósito anular la distancia que existe entre la multiplicidad consistente y la multiplicidad inconsistente y evitar así la presentación del vacío. De allí que en una situación "normal" el vacío se mantiene invisibilizado.

Sin embargo, el orden estructural del ser puede ser conmovido por un acontecimiento. Este término designa un suplemento imprevisible que excede las normas y saberes de una situación en tanto es muestra del vacío inherente al ser múltiple; es el índice de la inconsistencia. En ese sentido, una tesis fundamental de la ontología matemática (el Ilamado "teorema del punto de exceso") es que el estado de la situación excede siempre la situación misma. En tanto hay siempre más partes que elementos, la multiplicidad representativa es siempre superior a la multiplicidad presentativa ${ }^{12}$. Esta diferencia es el punto en el que reside lo que Badiou denomina el impasse ontológico que articula y a la vez separa a la ontología de la teoría filosófica del acontecimiento y del sujeto (Badiou, 1999: 99).

Badiou entonces no sólo se interesa por señalar en dicho impasse una carencia estructural, sino también el posible lugar de un acontecimiento. En efecto, para que el acontecimiento sea posible se requiere en primer lugar la determinación local de un sitio. Un sitio de acontecimiento se define ontológicamente como un múltiple en situación que es singular, es decir, que está presentado pero ninguno de sus elementos lo está, por lo cual no es representado por el estado de la situación (pertenece a la situación pero no está incluido en ella). También se puede señalar que está "al borde del vacío" debido a que es un múltiple que pertenece a la situación, pero lo que le pertenece a ese sitio está impresentado (Badiou, 1999: 197).

\footnotetext{
${ }^{11}$ Se debe distinguir este vacío ontológico del vacío con el que opera la filosofía en Badiou. La filosofía es concebida por él como un acto que consiste en la captación de verdades provenientes de las prácticas y pensamientos exteriores que la condicionan. Para ello, el discurso filosófico opera con la categoría de Verdad que es "vacía" en el sentido de que de sí misma no presenta nada. Por lo tanto, como señala Badiou, "el vacío de la categoría de Verdad, con $\mathrm{V}$ mayúscula, no es el vacío del ser, puesto que es un vacío operatorio, y no presentado" (Badiou, Condiciones, Buenos Aires: Siglo XXI, 2002, p. 59).

12 Considerando la distancia entre la estructura y la metaestructura, entre pertenencia e inclusión, Badiou elabora los conceptos decisivos de una tipología de las formas en las que se da el ser (los múltiples-en-situación): "normal" es un múltiple presentado y representado; en "excrecencia" está representado pero no presentado; "singular" es un múltiple presentado pero no representado (Badiou, 1999: 117).
} 
La presentación de este tipo de múltiple a-normal en una situación indica que ella es "histórica". Es decir, el acontecimiento sólo puede darse en una localización histórica específica. A la vez, no hay determinismo porque ningún sitio garantiza su ocurrencia, un sitio sólo puede ser vinculado al acontecimiento de modo retroactivo.

El acontecimiento es definido como un múltiple compuesto no sólo por todos los múltiples que pertenecen a su sitio, sino también por el múltiple de sí mismo (Badiou, 1999: 203). Por ejemplo, podríamos decir que la "Revolución Francesa" como acontecimiento es algo más que la enumeración de sucesos que lo conforman en un contexto determinado; la propia "Revolución Francesa" es un término del acontecimiento que él es. Pero, en tanto es caracterizado como un múltiple que se autopertenece, el acontecimiento es proscripto por los axiomas de la ontología matemática que de-limitan el ser. El pensamiento del acontecimiento depende entonces de lo que no-es-el-ser-en-tanto-que-ser, ese terreno a partir del cual el discurso filosófico -distinguible del discurso ontológico- reaparece y se organiza en torno a la renovación badiouana de las categorías de verdad y sujeto (Badiou, 1999: 24).

Dado que todo acontecimiento es evanescente por definición y posee un carácter indecidible desde la perspectiva de los saberes de una situación, para que su ocurrencia produzca efectos necesita que quienes son parte de ella se vinculen con él mediante una intervención militante que tome la decisión de nombrarlo (Badiou, 1999: 227). Por eso, Badiou señala que el impasse estructural sólo es visible como signo del acontecimiento retroactivamente y depende de la intervención de un sujeto: "el impasse del ser es en verdad el pase [passe] del Sujeto" (Badiou, 1999: 470-471).

Los sujetos del acontecimiento despliegan comprometida y fielmente las consecuencias de esta nominación en la situación a la cual pertenece el sitio. En efecto, para Badiou el sujeto no es un agente sustancial (no es un múltiple contado por la situación ya que el procedimiento del que participa es indiscernible), ni se identifica con un lugar vacío, sino que él es el nombre de las operaciones de indagación fieles a la traza del acontecimiento mediante las cuales conecta a esa traza (la nominación) tantos términos de la situación como sea posible. Como resultado de dicho proceso, es posible el surgimiento de una verdad singular que será la huella del acontecimiento en la situación, forzando así la transformación del estado previo de saberes ${ }^{13}$.

En suma, L'Être et l'événement teoriza que el sujeto no está dado, sino que depende de un acontecimiento excepcional y siempre se vincula a un procedimiento de verdad específico (es sujeto de la política, la ciencia, el arte o el amor). Badiou lo define como la instancia finita de lo infinito de una verdad: "un fragmento del proceso de verdad" (Badiou, 1999: 24). Al mismo tiempo, las operaciones

\footnotetext{
${ }^{13}$ En la exposición ontológica del acontecimiento como autopertenencia, éste puede parecer una ocurrencia milagrosa y aislada. Sin embargo, él posee una temporalidad propia, no es un acto puro sino que abre un proceso de consecuencias cuyas implicancias lógicas son abordadas por Badiou en profundidad en Lógicas de los Mundos, su segunda gran obra, publicada en 2006.
} 
implicadas en el proceso de subjetivación son fundamentales para el despliegue de una verdad en la situación.

\section{ReFLEXIONES FINALES: EL ACONTECIMIENTO Y LO SUBJETIVO EN BADIOU Y ALTHUSSER}

Si se comparan los desarrollos filosóficos de Badiou y Althusser a través de la idea de acontecimiento, hay que destacar que en el proyecto de Badiou dicha categoría posibilita pensar la cuestión del sujeto en política desde una visión que, si bien coincide con su ex maestro en descreer de la existencia de una sustancia o conciencia que actúe como Sujeto de la historia, no considera que pueda reducírselo a un efecto ideológico.

Al mismo tiempo, vale subrayar que la crítica althusseriana de la ideología no equivale a dejar de lado la cuestión de la práctica política. En ese sentido, Badiou sostiene la tesis de la existencia de lo subjetivo en el pensamiento de Althusser acerca de la política (a pesar de que éste jamás pudo haber formulado una teoría del sujeto en tanto consideraba que "sujeto" era una mera una noción ideológica), la cual surge del análisis de algunos de los textos de los años sesenta, la época más reconocida de su ex maestro. A pesar de que este período suele ser considerado como el momento de mayor dogmatismo althusseriano dado su énfasis en afirmar la necesidad de formular una teoría general que guíe la acción política de los militantes (actitud que él mismo catalogó posteriormente como una "desviación teoricista"), se puede decir que en esos años Althusser ya daba señales de su preocupación por aquello que puede surgir de manera imprevista en el ámbito de la política.

En efecto, en su texto "Contradicción y sobredeterminación", Althusser introduce la categoría de sobredeterminación tomando como punto de partida la referencia de Lenin al "eslabón más débil" en su análisis de las condiciones que rodearon al acontecimiento de la Revolución Rusa. A partir de este concepto, la contradicción en el marxismo no se concibe como unívoca, sino como una conjunción compleja de circunstancias, una contradicción sobredeterminada "pensable desde el momento en que se reconoce la existencia real, en gran parte específica y autónoma, irreductible, por lo tanto, a un puro fenómeno, de las formas de la superestructura y de la coyuntura nacional e internacional" (Althusser, 1971: 93). En este esquema, lo singular cobra valor en la historia en vez de ser considerado como una excepción a una regla última; se puede decir más bien que lo excepcional es la norma. La política se concibe entonces como algo más que la simple expresión de una estructura económica, pues jamás la contradicción se reduce a lo simple: "Ni en el primer instante ni en el último, suena jamás la hora solitaria de la 'última instancia'"

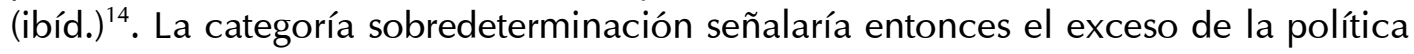

\footnotetext{
${ }^{14}$ Otras lecturas, incluso más habituales, enfatizan que para Althusser la contradicción no es equívoca o producto del mero azar. Ernesto Laclau (1987: 112) sostiene que la idea de sobredeterminación, índice de la inquietud del autor por registrar lo contingente, fue desapareciendo del discurso althusseriano al estar limitada en esa época por la necesidad apriorística y totalizante de la determinación en última instancia por lo económico. Desde la misma visión deconstructivista, Derrida sostiene: "Decir 'última instancia' en vez de infraestructura no cambia mucho y destruye o relativiza de manera radical justamente el hecho de que se tomen en cuenta las sobredeterminaciones. Todo lo que hay de interesante y
} 
y de la historia respecto de una concepción determinista del funcionamiento de una formación social. Asimismo, muestra a la idea de la contingencia como oportunidad para la política y la revolución.

En esta línea, en una evaluación del legado de su ex maestro, Badiou sostiene en la década de los noventa que las sobredeterminaciones acontecimentales (tal como él las denomina, ligando los términos de sobredeterminación y de acontecimiento) colocan a lo posible, es decir, a la política, en un lugar preponderante y son del orden de lo subjetivo. Según él, el término "subjetivo" significa, en la figura material del militante, un proceso de pensamiento de la política que se sustrae tanto a la objetividad científica como a lo ideológico-estatal donde el sujeto sería un mero efecto. La política es este proceso subjetivo que se vincula más bien con una toma de partido, con una elección sin una garantía que se pueda desprender del análisis reglado de la situación "pero que puede trazar en ella una trayectoria real" (Badiou, 2009: 56).

Una vez recuperada esta idea, es posible explorar y reconocer también la presencia de lo subjetivo en los textos sobre la práctica política de la última etapa de la obra de Althusser, la menos conocida (incluso por Badiou, quien se refiere escasamente a ella). Como se mencionó, la filosofía utilizada por Althusser para repensar la política revolucionaria en esa etapa es denominada "materialismo aleatorio". Ella implica una renuncia definitiva a la posibilidad de una teorización filosófica completa respecto de una realidad siempre contingente (o sobredeterminada). Este abandono de la legalidad dialéctica a la hora de pensar una sociedad y su historia viene acompañado de la aparición de un concepto similar al de sobredeterminación en los escritos althusserianos: la idea del encuentro aleatorio. En lugar de pretender explicar el desenvolvimiento de una totalidad y de intentar descifrar el rasgo de necesidad en cada fenómeno, la filosofía de lo aleatorio privilegia la singularidad de las prácticas vivas, entre ellas, la consideración de la práctica política como fundadora.

En ese sentido, a través de su examen del pensamiento maquiaveliano como parte de esta corriente, Althusser sostiene la primacía de la práctica política frente a la teoría. A diferencia de aquellos intérpretes que piensan que Maquiavelo produjo un discurso objetivo de las leyes de la política o una ciencia política (es decir, un discurso no ideológico y "sin sujeto"), Althusser considera que la particularidad del autor florentino reside en que no le interesa conocer "la naturaleza de las cosas", sino la singularidad de la cosa en singular, del caso. En efecto, él no pretende pensar a la política como un objeto de la teoría, sino más bien como aquello que la conmueve a través de un problema político concreto. Su estudio del problema de la unidad italiana obviamente incluye elementos teóricos pero éstos no remiten a una teoría general sino que sólo son "fragmentos" dispuestos en función de dicho problema (Althusser, 2004: 54-55).

fecundo en la lógica de la sobredeterminación se encuentra comprometido, reducido, aplastado por ese discurso sobre la 'última instancia'”. Cfr. Derrida, J. (2012), Política y amistad. Entrevistas con Michael Sprinter (2012), Buenos Aires, Nueva visión, pp. 46-47. 
En efecto, para Althusser, Maquiavelo es el primer teórico que piensa desde dentro de la coyuntura, aún sin haber reflexionado sobre este concepto. En principio, esto significaría enumerar todos los factores y circunstancias que rodean al caso. Pero, pensar bajo la coyuntura implica algo más: hay que someterse al problema que ella "impone", asumiendo el problema y la tarea histórica del momento (la unidad italiana, cuya forma de realización es el Príncipe). De este modo, los elementos de la coyuntura se convierten en fuerzas vivas y en conflicto, y las proposiciones teóricas sobre la política "quedan afectadas en su modalidad por su intervención en una coyuntura totalmente dominada por el problema político que ella plantea y por la práctica política que requiere para alcanzar el objetivo que se propone" (Althusser, 2004: 57).

El tipo de análisis que hace Maquiavelo desde dentro de la coyuntura política con el objetivo de fundar algo nuevo se distingue entonces de la pretensión de totalidad de la teoría e implica un desplazamiento desde el espacio de una teoría pura y anónima ("sin sujeto") al espacio de la práctica política, la cual sólo cobra sentido en relación con un "sujeto". En efecto, este análisis tiene sentido en cuanto exhibe un sitio o lugar vacío (el "eslabón más débil") en el cual se podrá posicionar y actuar un individuo o un grupo con el cometido de realizar su tarea política, es decir, aquellos a quienes podríamos llamar los "sujetos" o "agentes" de la práctica política (Althusser, 2004: 58). Maquiavelo, como vimos, considera que la forma política de su realización es un agente virtual, el Príncipe Nuevo, que con posteridad al acontecimiento de su advenimiento debe actuar estratégicamente en la situación para transformarla de forma duradera.

Asimismo, además de señalar el lugar del "sujeto" de la práctica política en el pensamiento maquiaveliano, Althusser se interesa por el papel del propio texto en el espacio de la práctica política en la que se sitúa. Al respecto, adscribe a la idea gramsciana de que El Príncipe es un manifiesto en el que el autor se posiciona y toma partido, escribe con la intención de sumar fuerzas a una causa. Por lo tanto, su novedoso estilo de escritura es un acto político en sí mismo, una práctica que se propone intervenir en la coyuntura y construir un sujeto (lo cual permitiría distinguirla de la vieja fórmula del "proceso sin sujeto" del Althusser más estructuralista).

Para Althusser, el posicionamiento inscripto en esta obra o "manifiesto" maquiaveliano es revolucionario porque el lugar que establece para su texto, para su punto de vista, no es el del Príncipe, sino el del pueblo. En la famosa dedicatoria de Maquiavelo a Lorenzo de Médici puede descubrirse que, pese a sus apariencias, el libro se dirige a la masa popular, dado que el proyecto es fundar un Estado nacional y popular, no una tiranía. "No se escribe un Manifiesto (...) para un individuo inexistente; un Manifiesto se dirige siempre a las masas para reunirlas en una fuerza revolucionaria" (Althusser, 2004: 61-62). En comparación con el Manifiesto Comunista donde se encontraría un único sujeto ya constituido, el proletariado, sobre cuya existencia se apoya la teoría y al cual el texto convoca a una tarea política; Althusser halla en El Príncipe una dualidad: hay un sujeto designado de la práctica política, el Príncipe, pero también un sujeto del punto de vista político, el pueblo, convocado proféticamente. 
Según Althusser, esta presentación de dos lugares alternados desemboca en un contenido utópico, pues se asume la necesidad de emprender una tarea política en condiciones históricas que no la garantizan y, a la vez, confía su realización a un agente desconocido, el Príncipe, cuyo advenimiento depende de un acontecimiento. La utopía maquiaveliana encuentra su espacio en la diferencia entre una tarea y transformación política necesaria y sus condiciones de realización que, si bien son posibles porque no hay un final de la política, son también impensables por depender de un evento aleatorio (Althusser, 2004: 85). La utopía entonces ya no puede ser viste necesariamente como un defecto o una falta de teoría, sino como aquello que fuerza las condiciones de posibilidad, un salto sobre los límites.

En resumen, a partir de la idea de un acontecimiento, Althusser y Badiou nos permiten repensar la subjetividad política en los momentos en que se ha derrumbado la confianza en la idea de la existencia de un sujeto político pre-constituido que trascienda la historia. Al mismo tiempo, vale destacar que en sus trabajos "pos" crisis del marxismo, fundamentalmente desde los años ochenta, aún si ambos son críticos respecto de los partidos comunistas subordinados a la influencia soviética, asumen posiciones teóricas que se mantienen fieles al proyecto emancipador del comunismo. Esto los diferencia claramente de otros intelectuales franceses que por aquellos años "renegaron" expresamente de anterior su militancia revolucionaria y viraron hacia posturas abiertamente conservadoras (principalmente, los llamados "nuevos filósofos").

El reconocimiento del contexto de crisis los empuja en efecto a replantearse la cuestión de la emancipación, razón por la cual tanto a Althusser como a Badiou se cuidan en no avasallar la singularidad de los sucesos de la política y se preocupan por concebir una filosofía que pueda "vaciarse" para hacer lugar a estas novedades aleatorias. En consecuencia, más allá de sus diferencias, en dicha época ambos realizan el intento de pensar una subjetividad militante que parte de la precariedad de la coyuntura y apuesta en ella a favor del posible acontecimiento yendo más allá de la certitud que puede deducirse del análisis o del saber de la condiciones presentes, puesto que, finalmente, el carácter transformador del acontecimiento sobre una situación sólo podrá leerse retroactivamente, a partir de sus efectos.

\section{BIBLIOGRAFÍA}

ALTHUSSER, Louis (1971). La revolución teórica de Marx. México: Siglo XXI.

ALTHUSSER, Louis (1974). "Ideología y aparatos ideológicos del Estado". Buenos Aires: Nueva Visión.

ALTHUSSER, Louis (2002). Para un materialismo aleatorio, Madrid: Arena.

ALTHUSSER, Louis (2003). Marx dentro de sus límites, Madrid: Akal.

ALTHUSSER, Louis (2004). Maquiavelo y nosotros, Madrid: Akal.

ALTHUSSER, Louis (2015). La Soledad de Maquiavelo, Buenos Aires, Akal. 
La idea de acontecimiento en las filosofías de Althusser y Badiou como forma de repensar la subjetividad política

BADIOU, Alain (2009). Compendio de metapolítica, Buenos Aires: Prometeo.

BADIOU, Alain (2008). Teoría del sujeto. Buenos Aires, Prometeo.

BADIOU, Alain (1990). ¿Se puede pensar la política? Buenos Aires, Nueva Visión.

BADIOU, Alain (1999). El ser y el acontecimiento. Buenos Aires, Manantial.

BADIOU, Alain (2016). "Le lien singular entre philosophie et stratégie politique", en LASOWSKI (comp.), Althusser et nous. Paris: PUF, pp. 31-34.

NEGRI, Antonio (2004), "Introducción. Maquiavelo y Althusser" en ALTHUSSER, Louis, Maquiavelo y nosotros. Madrid: Akal.

LACLAU, Ernesto (1987). "Formación social y sobredeterminación" en Hegemonía y estrategia socialista. Madrid. Siglo XXI.

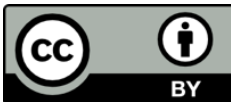

